\title{
Communicating behavioral genetics: Charting the limits of
}

\section{the genetic interpolation effect [version 1; peer review: 2}

\section{approved with reservations]}

\author{
Alexandre Morin-Chassé (it) \\ Université de Montréal, Montréal, Canada
}

V1 First published: 22 Nov 2016, 5:2744

https://doi.org/10.12688/f1000research.10032.1

Latest published: 29 Jan 2018, 5:2744

https://doi.org/10.12688/f1000research.10032.2

\section{Abstract}

Background: Scientific research has linked genetic predispositions to complex social behaviors and orientations. Recent empirical work in science communication suggests that the dissemination of these research findings can impact on public beliefs about the influence of genetics. The genetic interpolation hypothesis posits that exposure to this type of news causes the public to update their views about the influence of genetics on human beings and to infer greater genetic causation for other social traits that are not mentioned in the news content. The main purpose of this study is to test whether the genetic interpolation effect also emerges following exposure to a soft treatment: a short summary paragraph rather than a real news article. It also tests if specifying that a particular gene has a marginal effect succeeds at moderating the genetic interpolation effect. Finally, the study tests a counter-hypothesis: instead of resulting from belief updating, the genetic interpolation effect is triggered by the simple act of thinking about genetics shortly before reporting beliefs. Methods: In total, 2080 respondents were recruited from a pre-existing online panel and were randomly split into four experimental groups: group 1) no message; group 2) a paragraph about how genes can impact on voting behavior; group 3 ) the same paragraph as group 2 , plus an indication that the effect of a particular gene is small; group 4) a paragraph about how genetics impact on physical traits such as eye color. Subjects were then asked to evaluate the role of genetics in causing three traits: voting at election; intelligence; and natural hair style (curly or straight). Results: The analyses reveal no evidence supporting the genetic interpolation hypothesis, the moderation hypothesis or the counter-hypothesis. Conclusion: Overall, the results suggest that exposure to a paragraph describing how genes can impact on complex social behavior is not sufficient to trigger the genetic interpolation effect.

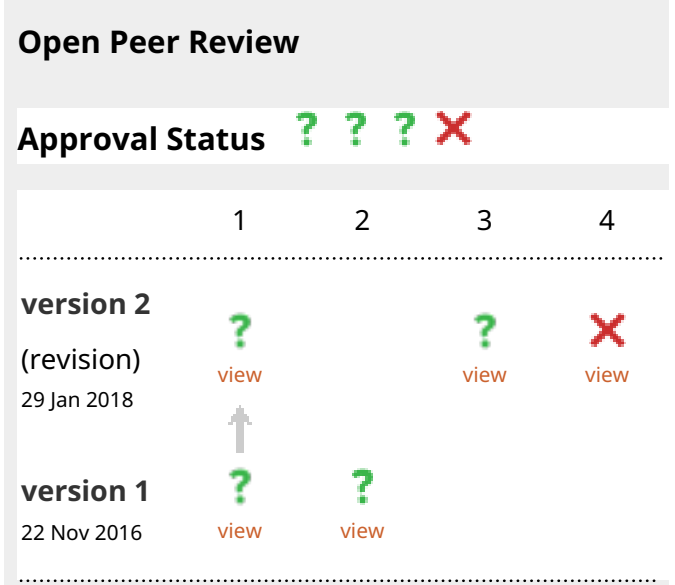

1. Brian M. Donovan, Biological Sciences Curriculum Study, Colorado Springs, USA

2. Kostas Kampourakis, University of Geneva, Geneva, Switzerland

3. Matteo Farinella , Columbia University in the City of New York, New York, USA

4. Fabien Medvecky, University of Otago,

Dunedin, New Zealand

Any reports and responses or comments on the article can be found at the end of the article. 


\section{Keywords}

science communication, public understanding of science, behavior genetics, genetic attribution, biased assimilation, genetic interpolation

effect, media effects, survey experiment

\section{Corresponding author: Alexandre Morin-Chassé (alexandre.morin.chasse@umontreal.ca) \\ Competing interests: No competing interests were disclosed.}

Grant information: Data collected by Time-sharing Experiments for the Social Sciences, NSF Grant 0818839, Jeremy Freese and James Druckman, Principal Investigators. The author also benefited from a Ph.D. Scholarship awarded by the Fonds de recherche du Québec Société et culture at the time the survey was fielded.

Copyright: ( 2016 Morin-Chassé A. This is an open access article distributed under the terms of the Creative Commons Attribution License, which permits unrestricted use, distribution, and reproduction in any medium, provided the original work is properly cited.

How to cite this article: Morin-Chassé A. Communicating behavioral genetics: Charting the limits of the genetic interpolation effect [version 1; peer review: 2 approved with reservations] F1000Research 2016, 5:2744

https://doi.org/10.12688/f1000research.10032.1

First published: 22 Nov 2016, 5:2744 https://doi.org/10.12688/f1000research.10032.1 


\section{Background}

The field of behavioral genetics works at improving scientific understanding of human and animal social behaviors by investigating whether these behaviors are partly influenced by genetic predispositions. The causal framework that commonly underlies behavior genetics takes the form of a chain reaction, linking genes, at one end, to neural processes, mental abilities and temperament, personality traits, world views, attitudes, and behaviors ${ }^{1,2}$. Survey research and focus groups suggest that the public generally adheres to a belief system that is consistent with this causal framework $^{3-5}$. Indeed, on average, people attribute a great role to genetics in explaining biological differences (i.e., eye color, height), a moderate influence for talents and social orientation (i.e., intelligence, sexual orientation), and a weak influence for complex social behavior (i.e., having debts, preferring Apple to Microsoft $)^{6}$. However, the media sometimes presents research findings in a way that sharply contrasts with both the public understanding of genetics and actual research conclusions. Indeed, when paying attention to the language science reporters choose to describe research findings, it is often unclear whether the influence of genetics is deterministic, prominent, moderate, or marginal ${ }^{7,8}$.

Many academics have expressed concern over the risk that the oversimplification of genetic causation in the mass media could lead the public to misinterpret research findings ${ }^{9-11}$. Recent empirical works in the field of science communication have offered initial support for this concern. It is not uncommon to see a news story reporting on the results of a scientific study suggesting that genetics can influence complex social behavior or orientation X. Experimental studies have tested how people react to this kind of news ${ }^{6}$. Two findings arise from this research. First, there is evidence of a persuasion effect: people exposed to this information increase the influence they attribute to genetics in explaining the characteristic X described in the article. However, the results also show that disseminating behavioral genetics leads some members of the public to infer greater genetic causation for other complex social traits, which were not the focus of the study presented. This side-effect has been called the genetic interpolation effect.

It is presumed that people infer greater genetic causation for other traits because they update their belief system about the overall role that genetics plays in defining social traits. The psychological mechanism at play here is likely the anchoring and adjustment heuristic ${ }^{12,13}$. This heuristic is a cognitive shortcut people often use in their everyday life to cope with uncertainty. Many individuals, even expert geneticists, would feel ambivalent if they had to assess the overall influence genetics has on a social orientation or a social behavior. Arguably, reading a news article presenting research findings from behavior genetics can offer a valuable piece of information to complete this task. Some people may react to behavior genetics by thinking to themselves that "if genetics is strong enough to have a significant influence on this complex social trait, then its general influence on other social traits must be stronger than I had imagined," thus causing them to infer greater genetic influence for other complex characteristics not mentioned in the news article content.
The purpose of this study is threefold. First, the main goal is to test if the persuasion effect $(\mathrm{H} 1)$ and the genetic interpolation effect (H2) also emerge following exposure to a softer treatment. Addressing this issue is necessary to better capture what kind of message can trigger the genetic interpolation effect. While previous studies exposed participants to real news articles, here subjects are exposed to one paragraph claiming that genes can influence a complex social behavior: voting or abstaining at elections. Second, the experiment was designed to test whether clarifying that a particular gene involved in causing this behavior only has a marginal effect and can moderate the size of the persuasion effect (H3). If this was found to be the case, one could expect it to result in much weaker belief updating for other nonrelated traits, thus contributing to moderating the size of the genetic interpolation effect as well (H4). Finally, this study was also designed to test a counter-hypothesis, an alternative explanation for the genetic interpolation effect. This alternative explanation posits that, instead of resulting from belief updating, the genetic interpolation effect is due to the simple fact that thinking about genetics shortly before reporting beliefs makes the genetic argument more accessible to participants' minds (H5). If this was the case, being reminded that genetics can influence various physical traits - a "placebo" message - would suffice to move participants' average response.

\section{Methods}

This study was conducted as part of the Short Study Program of Time-Sharing Experiments in the Social Sciences. A web survey was fielded by the firm Government for Knowledge during the month of August 2013. A sample of 2080 respondents was recruited from a pre-existing panel, with a response rate of 62.6\% (AAPOR RR3; see Data availability). No participants were excluded from this study. Participants were randomly assigned to one of four experimental conditions without knowing it. Table 1 reports the stimulus for each experimental condition. Table 2 reports a randomization check.

Following treatment exposure, subjects were asked how much they believe genetics (as opposed to the environment) impacts on three features: "turning out to vote," "intelligence," and "natural hairstyle (curly or straight)." Items were presented in random order. Table 3 shows the eleven-point response scale. We report all measures and manipulations.

\section{Statistical analysis}

The statistical analyses were performed using Stata 14. H1, H2 and $\mathrm{H} 5$ require testing whether the mean genetic attribution for a trait is higher in a specific treatment group compared to the control group. We test these hypotheses by running various Welch's t-tests, which, contrary to Student's t-tests, do not assume that the two groups under comparison have equal variances. Furthermore, $\mathrm{H} 3$ and $\mathrm{H} 4$ predict moderation effects. These are tested by fitting OLS regression models that predict the genetic attribution for the relevant trait with three dummy variables, one for each group. We then use the functions margins, $d y d x$ and lincom to compare coefficient values and perform difference in difference tests (statistical threshold, $\mathrm{p}<0.05$ two-tailed). 


\begin{tabular}{|l|l|l|l|l|}
\hline Table 1. Experimental conditions. \\
\hline 1 & Group & Hypotheses & Stimuli \\
\hline 2 & No stimulus \\
\hline 3 & H3 and H4 & $\begin{array}{l}\text { "A new field of research, called genopolitics, investigates the influence of } \\
\text { genetics on political attitudes and behaviors. Political scientists have found the } \\
\text { act of voting to be associated with prosocial personality traits like altruism and } \\
\text { open-mindedness. Geneticists have further uncovered that these traits are } \\
\text { themselves partly shaped by one's genetic makeup. This research has led to } \\
\text { a growing number of studies showing that genes indirectly influence political } \\
\text { participation in general, and voter turnout in particular." }\end{array}$ \\
\hline $\begin{array}{l}\text { Same as Group } 2+\text { "For example, one study shows that turnout is } 5 \% \text { higher } \\
\text { among people with one form of the MAOA gene than among people with the } \\
\text { other form of the gene." } \\
\text { "Between 1993 and 2003, scientists from around the world have worked } \\
\text { on coding the chemical components of human DNA. Now that the Human } \\
\text { Genome Project is complete, geneticists strive to understand the roles played } \\
\text { by specific genes. For example, research finds evidence that eye color, } \\
\text { hair color and whether someone has attached or free hanging earlobes are } \\
\text { physical traits that are strongly influenced by genetics." }\end{array}$ \\
\hline 45
\end{tabular}

\section{Table 2. Randomization Check.}

\begin{tabular}{|l|c|c|c|c|c|}
\hline Variable & Gr 1 & Gr 2 & Gr 3 & Gr 4 & $\begin{array}{c}\text { All } \\
\text { sample }\end{array}$ \\
\hline Male & \% & \% & $\%$ & $\%$ & \% \\
\hline Female & 49.0 & 46.8 & 50.4 & 48.1 & 48.6 \\
\hline 18-24 & 51.0 & 53.2 & 49.6 & 51.9 & 51.4 \\
\hline 25-34 & 8.5 & 7.6 & 8.0 & 7.4 & 7.9 \\
\hline 35-44 & 12.3 & 13.5 & 13.4 & 14.2 & 13.4 \\
\hline 45-54 & 15.2 & 14.7 & 17.3 & 13.9 & 15.2 \\
\hline 55-64 & 22.4 & 19.1 & 17.7 & 19.8 & 18.8 \\
\hline 65-74 & 16.3 & 17.7 & 15.4 & 15.3 & 16.2 \\
\hline 75+ & 6.6 & 4.8 & 6.6 & 7.2 & 16.4 \\
\hline Less than HS & 7.6 & 8.0 & 8.4 & 8.1 & 8.0 \\
\hline High School & 29.2 & 29.7 & 28.2 & 28.7 & 28.9 \\
\hline Some College & 28.7 & 28.3 & 27.2 & 29.2 & 28.4 \\
\hline Univ. Degree & 34.5 & 33.9 & 36.2 & 34.0 & 34.7 \\
\hline Less than 25K & 16.7 & 15.1 & 15.4 & 16.8 & 16.0 \\
\hline 25K to 50K & 23.0 & 24.3 & 21.2 & 22.2 & 22.6 \\
\hline 5OK to 75K & 20.1 & 20.9 & 19.5 & 18.3 & 19.7 \\
\hline 75K to 100K & 13.5 & 12.9 & 15.2 & 16.3 & 14.5 \\
\hline 100K to 125K & 11.6 & 12.7 & 14.0 & 13.3 & 12.9 \\
\hline 125 and + & 15.2 & 14.3 & 14.8 & 13.1 & 14.3 \\
\hline Extr Lib & 3.2 & 3.2 & 3.3 & 3.9 & 3.4 \\
\hline Liberal & 14.2 & 12.7 & 14.0 & 12.6 & 13.4 \\
\hline Slightly Lib & 8.2 & 11.2 & 11.7 & 12.4 & 10.9 \\
\hline Moderate & 32.1 & 32.7 & 35.0 & 31.6 & 33.1 \\
\hline Slightly Cons & 11.8 & 14.1 & 13.0 & 13.1 & 13.1 \\
\hline Conservative & 23.9 & 20.5 & 17.1 & 21.4 & 21.4 \\
\hline Extr Cons & 5.9 & 3.4 & 3.7 & 3.7 & 4.2 \\
\hline Refuse & 0.8 & 2.2 & 1.2 & 1.3 & 1.4 \\
\hline N of obs. & 527 & 498 & 514 & 541 & 2.080 \\
\hline
\end{tabular}




\section{Results}

Table 4 presents the results of the experiment. The first element worth noticing is that the mean genetic attribution for turnout in the control group is much higher than what one would intuitively expect, with a mean of 27.24 on a scale ranging from 0 to 100 . We ran Welch t-tests to assess the impact of treatment exposure. The second column of Table 3 presents the results of comparisons between the group exposed to genopolitics (Group 2) and the control group (Group 1). The results for the turning out to vote item show evidence of a statistically significant, but substantially small persuasion effect, offering support for $\mathrm{H} 1$. However, although the average genetic attribution for intelligence in Group 1 is higher than in the control group, this difference is too small to reach statistical significance. Therefore, we must reject $\mathrm{H} 2$.

Results presented in the third column indicate that there is still a significant persuasion effect among the group exposed to the paragraph insisting on the marginal effect of a particular gene (Group 3). The fourth column presents the result of a difference in difference comparison, testing whether adding this word of caution about the marginal influence of a specific gene succeeds at moderating the persuasion effect. The results displayed in the first row of this column indicate no significant difference between the persuasion effects caused by these two paragraphs about genopolitics, thus leading us to reject $\mathrm{H} 3$. Considering that both $\mathrm{H} 2$ and $\mathrm{H} 3$ are rejected, it should be no surprise to find that the second row of the fourth column offers no support for H4 either. Finally, the fifth column of Table 3 suggests that, contrary to what H5 predicts, presenting a paragraph describing how genetics impacts on human physical traits is not sufficient to generate the genetic interpolation effect.
Noticeably, the results also present an unanticipated finding: compared to Group 1, Group 2 and Group 3 show lower average genetic attribution for natural hair style. The genetic interpolation hypothesis offers no explanation for this phenomenon, but something else may be at play here.

Survey satisficing occurs when respondents use strategies and cognitive shortcuts to offer a survey response without making all the efforts to ensure that the answer they give best corresponds to their opinion, their point of view or, as it is the case here, their belief ${ }^{14}$. Strength-lining is a form of satisficing that consists of picking the same answer repeatedly for different questions without differentiating between them ${ }^{15}$. A closer look at the response distribution offers reasons to believe that exposure to either of the two genopolitics treatment paragraphs demotivated some participants to offer honest answers. Indeed, in both of these groups, approximately $10 \%$ of respondents picked the same response option for our three question items; in comparison, the equivalent figures for the control group and the group exposed to the placebo treatment are $6.45 \%$ and $6.65 \%$ (pairwise differences are statistically significant at $\mathrm{p}<0.05$ ). But crucially, most straightliners answered the middle option category (50\% genetics and 50\% environment) for all three questions.

Greater satisficing thus pulls the average genetic attribution response further toward the center of the scale. This unexpected finding may partly explain the surprising negative effect observed for the hair style response item. Admittedly though, it might as well partly account for the positive effect observed on the voting at election item, a positive effect that what would otherwise be assimilated to the persuasion effect.

Table 3. Response scale used for each question.
\begin{tabular}{|l|l|l|l|l|l|l|l|l|l|l|l|}
\hline Influence of genetics & $0 \%$ & $10 \%$ & $20 \%$ & $30 \%$ & $40 \%$ & $50 \%$ & $60 \%$ & $70 \%$ & $80 \%$ & $90 \%$ & $100 \%$ \\
\hline Influence of the environment & $100 \%$ & $90 \%$ & $80 \%$ & $70 \%$ & $60 \%$ & $50 \%$ & $40 \%$ & $30 \%$ & $20 \%$ & $10 \%$ & $0 \%$ \\
\hline & $\bigcirc$ & $\bigcirc$ & $\bigcirc$ & $\bigcirc$ & $\bigcirc$ & $\bigcirc$ & $\bigcirc$ & $\bigcirc$ & $\bigcirc$ & $\bigcirc$ & $\bigcirc$ \\
\hline
\end{tabular}

Table 4. Effect of treatment exposure on average genetic attribution.

\begin{tabular}{|c|c|c|c|c|c|c|c|c|c|c|}
\hline \multirow[b]{3}{*}{ Trait } & & & \multicolumn{8}{|c|}{ Group comparisons } \\
\hline & \multicolumn{2}{|c|}{ Gr1 } & \multicolumn{2}{|c|}{ (Gr2 - Gr1) } & \multicolumn{2}{|c|}{ (Gr3 - Gr1) } & \multicolumn{2}{|c|}{ (Gr3 - Gr1) - (Gr2 - Gr1) } & \multicolumn{2}{|c|}{ (Gr4 - Gr1) } \\
\hline & Mean & SD & Mean diff. & SE & Mean diff. & SE & Diff. in diff. & SE & Mean diff. & SE \\
\hline $\begin{array}{l}\text { Voting } \\
\text { Intelligence } \\
\text { Hairstyle }\end{array}$ & $\begin{array}{l}27.24 \\
56.91 \\
80.85\end{array}$ & $\begin{array}{l}26.20 \\
23.81 \\
24.54\end{array}$ & $\begin{array}{c}4.12^{\star} \\
1.07 \\
-4.23^{\star}\end{array}$ & $\begin{array}{l}1.70 \\
1.46 \\
1.68\end{array}$ & $\begin{array}{c}4.15^{\star} \\
0.17 \\
-3.96^{\star}\end{array}$ & $\begin{array}{l}1.68 \\
1.48 \\
1.69\end{array}$ & $\begin{array}{c}0.03 \\
-0.90 \\
0.27\end{array}$ & $\begin{array}{l}1.72 \\
1.48 \\
1.70\end{array}$ & $\begin{array}{c}-2.11 \\
1.79 \\
1.23\end{array}$ & $\begin{array}{l}1.66 \\
1.44 \\
1.51\end{array}$ \\
\hline
\end{tabular}

Note: ${ }^{*} \mathrm{p}<0.05 ;{ }^{* *} \mathrm{p}<0.01$. Two-tailed tests. 


\section{Discussion}

The main purpose of this study was to test whether exposure to a paragraph on behavior genetics can generate the genetic interpolation effect. The experimental evidence presented above offers no indication that this is the case. However, both paragraphs presenting behavior genetics findings were successful at moving reported beliefs about how much genetics impacts on the trait presented in the paragraph - here, voting at elections. Yet, a closer look at the response distribution suggests that we should not overemphasize this finding, for a part of it may be attributable to lower response quality. Furthermore, our results indicate that insisting on the small role of a particular gene fails at moderating this persuasion effect. Finally, the results suggest that making genetic causation more accessible to the mind using a placebo message does not suffice to produce the persuasion or the genetic interpolation effect.

Nevertheless, the key finding here is related to the fact that the genetic interpolation effect was not exhibited. One likely explanation for this relates to the small size of the persuasion effect, more or less 4 percentage points. For the sake of comparison, in previous experiments, participants exposed to a whole news article about genopolitics showed persuasion effects ranging between 10 and 15 percentage points ${ }^{6}$. With this in mind, it seems plausible to interpret this null finding as an indication that a short paragraph on behavior genetics is a treatment condition that is not strong enough to cause people to update their general belief framework about the influence of genetics.

Additional research is needed to clarify the reasons why neither the moderation hypothesis nor the counter-hypothesis were confirmed. Indeed, it remains unclear whether these hypotheses would be supported if subjects were exposed to a real, and presumably more credible, news article instead. In spite of its null finding, the present study will hopefully help orient future research investigating how people react to behavior genetics. Indeed, our results help to chart the limits of the genetic interpolation effect by showing that not every type of message about behavior genetics succeeds in triggering this side-effect.

\section{Ethical approval}

The study was approved by the Comité d'éthique de la recherche en arts et en sciences of the Université de Montréal.

\section{Data availability}

The dataset and the pollster report for this study are hosted on the Open Science Framework: DOI: 10.17605/OSF.IO/2UBP2 ${ }^{16}$.

\section{Author contributions}

AMC conducted all the work related to this study.

\section{Competing interests}

No competing interests were disclosed.

\section{Grant information}

Data collected by Time-sharing Experiments for the Social Sciences, NSF Grant 0818839, Jeremy Freese and James Druckman, Principal Investigators. The author also benefited from a Ph.D. Scholarship awarded by the Fonds de recherche du Québec - Société et culture at the time the survey was fielded.

\section{Acknowledgments}

The author is grateful to the Center for Research on Ethical, Legal and Social Implications of Psychiatric, Neurologic, and Behavioral Genetics, based at Columbia University, for offering a stimulating research environment during his stay as a postdoctoral researcher.
1. Dawes $\mathrm{C}$, Cesarini D, Fowler $\mathrm{JH}$, et al:: The relationship between genes, psychological traits, and political participation. American Journal of Political Science. 2014; 58(4): 888-903.

Publisher Full Text

2. Mondak JJ, Hibbing MV, Canache D, et al.: Personality and civic engagement: An integrative framework for the study of trait effects on political behavior. American Political Science Review. 2010; 104(1): 85-110. Publisher Full Text

3. MORI survey of the People's Panel: Public attitudes to human genetic information. Technical report, Human Genetics Commission, 2001. Reference Source

4. Shostak S, Freese J, Link BG, et al: The politics of the gene: Social status and beliefs about genetics for individual outcomes. Soc Psychol Q. 2009; 72(1): 77-93. PubMed Abstract I Publisher Full Text | Free Full Text

5. Parrott RL, Silk KJ, Condit C: Diversity in lay perceptions of the sources of human traits: genes, environments, and personal behaviors. Soc Sci Med. 2003; 56(5): 1099-1109.

PubMed Abstract | Publisher Full Text

6. Morin-Chassé A: Public (mis)understanding of news about behavioral genetics research: A survey experiment. BioScience. 2014; 64(12): 1170-1177. Publisher Full Text

7. Cappella JN, Mittermaier DJ, Weiner J, et al.: Framing genetic risk in print and broadcast news: A content analysis. In 93rd Annual meeting of the National Communication Association. Chicago IL. Reference Source

8. Brechman J, Lee CJ, Cappella JN: Lost in translation? a comparison of cancergenetics reporting in the press release and its subsequent coverage in lay press Sci Commun 2009: 30(4): 453-474.

PubMed Abstract | Publisher Full Text | Free Full Text

9. Nelkin D, Lindee SM: The DNA Mystique: The Gene as a Cultural Icon. WH Freeman and Co, 1995

Reference Source

10. Peters T: Playing God?: Genetic Determinism and Human Freedom. Routledge, 2014.

Reference Source

11. Krimsky S, Gruber J: Genetic Explanations: Sense and Nonsense. Harvard University Press, 2013

Reference Source

12. Tversky A, Kahneman D: Judgment under uncertainty: Heuristics and biases. In Dirk Wendt and Charles Vlek, editors, Utility, Probability, and Human Decision Making. D. Reidel Publishing Company, 1975; 11: 141-162. Publisher Full Text

13. Furnham A, Boo HC: A literature review of the anchoring effect. $J$ Socio Econ. 2011; 40(1): 35-42. Publisher Full Text

14. Krosnick JA: Response strategies for coping with the cognitive demands of attitude measures in surveys. Appl Cogn Psychol. 1991; 5(3): 213-236. Publisher Full Text

15. Kaminska O, McCutcheon AL, Billiet J: Satisficing among reluctant respondents in a cross-national context. Public Opin Q. 2010; 74(5): 956-984. Publisher Full Text

16. Morin-Chassé A: Communicating behavior genetics: Charting the limits of the genetic interpolation effect. Open Science Framework, 2016. Data Source 


\section{Open Peer Review}

\section{Current Peer Review Status: ? ?}

\section{Version 1}

Reviewer Report 10 January 2017

https://doi.org/10.5256/f1000research.10808.r17905

(C) 2017 Kampourakis K. This is an open access peer review report distributed under the terms of the Creative Commons Attribution License, which permits unrestricted use, distribution, and reproduction in any medium, provided the original work is properly cited.

\section{Kostas Kampourakis \\ Section of Biology \& University Teacher Training Institute, University of Geneva, Geneva, Switzerland}

This is a review of the manuscript titled "Communicating behavioral genetics: Charting the limits of the genetic interpolation effect". I have strong reservations about the manuscript on various grounds, and I hope that the author will manage to revise it.

First of all, the author needs to justify why we should care at all about what he calls "the genetic interpolation effect". With this, I do not mean to suggest that we should not care. Rather, I suggest that the author needs to make a stronger case for this. The author writes that "Experimental studies have tested how people react to this kind of news", but the author only cites his own previous work. Are these author's studies all the experimental studies on this topic? Or are there others that have not been mentioned? Is this effect well-established in research? Or is it something recently "discovered"?

The author writes that "This side-effect has been called the genetic interpolation effect." By whom? Why? How strong this effect is? How prevalent? No references are given and so we have no idea about these. I am also wondering about the name itself. The author writes that "However, the results also show that disseminating behavioral genetics leads some members of the public to infer greater genetic causation for other complex social traits, which were not the focus of the study presented." This looks more like extrapolation to me. Perhaps the author is right, and my point is not to question the choice of the name. Rather my point is to suggest that we need more information about this effect, which is the focus of the article.

There are studies by Ilan Dar Nimrod (http://sydney.edu.au/science/people/ilan.darnimrod.php) that I find very relevant and that should have at least been discussed in this article. Celeste Condit has also conducted a few studies on how people interpret news articles on genetics. Both of these scholars would be appropriate reviewers for this article. My suggestion would be for the author to briefly review the findings of their research, and relate his own research to those in order to make more explicit what his contribution is. Individual studies may make interesting contributions, but generalizations are not easy to make even if the sample is 
large.

Some more information about the anchoring and adjustment heuristic would be useful. These are not sufficiently described in the current article, and so one must read the cited articles in order to understand what it is about and how it relates to the research presented therein.

There are some problems with the hypotheses made by the author. Does $\mathrm{H} 2$ presuppose $\mathrm{H} 1$ ? This is not clear. My understanding is that it does, i.e. that people first have to increase the influence they attribute to genetics in explaining a characteristic after reading the article, in order to subsequently infer greater genetic causation for other complex social traits. This is at least the inference I make from author's description of $\mathrm{H} 3$ and $\mathrm{H} 4$. It is of course plausible that this is not the assumption made by the author. But then the author should explain why this is the case. Even if I am wrong, the author should ensure that readers will not make the same mistake I have made.

Commenting on the statistical methods used falls outside my modest area of expertise. Therefore, I will only comment on the conclusions made assuming that the statistical analysis is appropriate.

The author writes: " A sample of 2080 respondents was recruited from a pre-existing panel, with a response rate of 62.6\%" Does this mean that approximately 1302 people responded? If yes, why isn't this made clear so that we know what the sample of the study was? That $38 \%$ of those asked declined to respond may be interesting for those conducting this kind of surveys. However, in this case we only need to know the actual sample size; how many people were asked to participate is of secondary importance.

I am wondering how the reliability and the validity of the inferences made from participants responses was established. Did the author ask experts to read the stimuli and confirm that they are appropriate to measure what the author intends to measure? Were these stimuli used in a pilot study of some kind before this study? For instance the author writes that (Table 1) "Between 1993 and 2003, scientists from around the world have worked on coding the chemical components of human DNA." The expression "coding the chemical components" makes no sense to me. What happened during the HGP was that researchers developed methods to find the sequence of the chemical components (bases $A, T, C, G$ in nucleotides) of the human genome. Decoding this sequence, i.e. finding the information encoded therein, is something that they are still working on. The expression "coding the chemical components" could be very misleading and I do not know if this was done in purpose or accidentally.

On the same topic, I do not see why the author would expect that $\mathrm{H} 5$ would be confirmed. The author concludes that "Finally, the fifth column of Table 3 suggests that, contrary to what H5 predicts, presenting a paragraph describing how genetics impacts on human physical traits is not sufficient to generate the genetic interpolation effect." There are numerous studies that provide evidence that people intuitively tend to think about biological characteristics as influenced, if not determined, by genes. People tend to take for granted that "physical traits" "are strongly influenced by genetics". Confusion begins when people mistakenly start wondering how much of a trait is due to genes or due to environment, as they often fail to understand that it is the interaction of the two that brings about a phenotypic outcome and thus they cannot be separated. Now, it seems to me that what the author is testing here is another extrapolation effect: whether a statement about biological traits would form the basis for inferences for a behavioural trait. This is interesting but seems to me to be a different effect than the one that the author wants to test, 
rather than "an alternative explanation for the genetic interpolation effect."

Based on all this, I suggest that the author carefully reconsiders his conclusions. I am not at all convinced that this conclusion is valid: "it seems plausible to interpret this null finding as an indication that a short paragraph on behavior genetics is a treatment condition that is not strong enough to cause people to update their general belief framework about the influence of genetics." I am inclined to think that when it comes to genetics even a replacement effect is possible, i.e. reading a highly deterministic headline could make people think in more deterministic terms about genetics. There is no research on that, but some relevant research suggests that this could be possible (e.g. Ecker , U. K. , Lewandowsky, S. , Chang , E. P. , \& Pillai , R. ( 2014 ). The effects of subtle misinformation in news headlines. Journal of Experimental Psychology: Applied,20 ( 4 ), 323 - 335.). This is just speculation based on personal experience, and we need research to draw conclusions. The conclusions of this article seem to point to the opposite direction, but I am not sure about their validity. The author should work more and reconceptualize the available data in order to be more convincing that his conclusions are valid.

Therefore, I have strong reservations about the quality and the conceptual foundations of this study, and I would like to see if the author will manage to address my concerns.

Competing Interests: No competing interests were disclosed.

\section{I confirm that I have read this submission and believe that I have an appropriate level of expertise to confirm that it is of an acceptable scientific standard, however I have significant reservations, as outlined above.}

Reviewer Report 08 December 2016

https://doi.org/10.5256/f1000research.10808.r18117

(C) 2016 Donovan B. This is an open access peer review report distributed under the terms of the Creative Commons Attribution License, which permits unrestricted use, distribution, and reproduction in any medium, provided the original work is properly cited.

\section{Brian M. Donovan}

Biological Sciences Curriculum Study, Colorado Springs, CO, USA

In "Communicating behavioral genetics: Charting the limits of the genetic interpolation effect" the authors report research from an experimental trial run online which explores how exposure to genetic information about human behaviors affects beliefs about the genetic (versus environmental) determinants of social behavior. This topic is an important area for research given the often widespread misunderstanding of genetics and behavior, which is both perpetuated through genotype in the media and also through science education. Furthermore, genetic determinism has been shown to be implicated in a variety of social prejudices by social 
psychologists. Consequently, the null findings reported in this research could be significant to many science communication scholars, science education researchers, or social psychologists interested in public understanding of genetics. To make that contribution more clear, however, the author needs to attend to some theoretical and methodological issues in this present draft of the manuscript.

Those issues are:

A clearer and stronger theoretical and/or empirical rationale for testing a softer treatment to chart the limits of the genetic interpolation effect.

Clearly defined confirmatory and exploratory hypothesis tests which are then mapped onto a post-hoc power analysis to demonstrate that the trial was well-powered, and thus, that the null findings are significant.

More care needs to be taken in interpreting the null findings. At present, the authors provide a partial explanation for the null findings with the idea of straightlining. However, by their own account this explanation might only capture $6-10 \%$ of the null effect.Thus, a more convincing explanation for the null effect is needed to guide future research.

In sum, the significance of a null-experimental finding should be judged on its ability to guide future research. Null findings, when well powered, should help researchers decide which paths NOT to go down. And, they should provide some theoretical reason for why such paths lead nowhere. At present, the manuscript does not accomplish this task. But, with major revisions it might be able to make this contribution. Thus, I recommend that the study be approved with reservations. If all of the issues outlined below in my critique of the piece can be addressed by the author, then I think this piece will make a significant contribution to the public understanding of genetics.

\section{Theoretical issues:}

I would have liked to see a more nuanced discussion about the possible mechanisms which link the reading of behavioral genetics research to genetic attributions of complex human traits. For example, if the genetic interpolation effect is actually based on anchoring and adjustment, then one would expect that individual differences in people's prior conceptions about the genetic basis of human traits might moderate the activity of the genetic interpolation effect.

For example, the author hypothesizes that "Some people may react to behavior genetics by thinking to themselves that "if genetics is strong enough to have a significant influence on this complex social trait, then its general influence on other social traits must be stronger than I had imagined," thus causing them to infer greater genetic influence for other complex characteristics not mentioned in the news article content."

But, what if people already strongly believe that social traits are caused by genes. In this situation, a ceiling effect might exist, thus preventing the statistical detection of the genetic interpolation effect. Under a ceiling effect model, we would expect a Treatment x Prior genetic belief interaction, where those who do not attribute social traits to genes before reading are affected by the experiment and those who do are not impacted by treatment. Conversely, it could also be the case that those who are generally averse to the idea that genes cause human social traits are 
inoculated against any impact that reading about behavioral genetics might have on genetic interpolation. Thus, the Treatment $x$ Prior genetic belief interaction on the genetic interpolation effect could be the opposite of what I have previously stated.

The point is that prior knowledge and beliefs could have washed out the treatment effects and produced the null findings of this experiment. And, there is a large body of reading comprehension research which shows that the meaning people construct from readings varies with their prior knowledge. Hence, to interpret these null findings some discussion of the impact of prior knowledge is needed both in the theoretical motivation for the study and during the discussion. Indeed, the authors allude to this need when they discuss an unexpected finding in their results. They state:

"Noticeably, the results also present an unanticipated finding: compared to Group 1, Group 2 and Group 3 show lower average genetic attribution for natural hair style. The genetic interpolation hypothesis offers no explanation for this phenomenon, but something else may be at play here."

Perhaps the explanation is that individual differences in people's prior beliefs caused the null effect? The authors partly explain this finding with straightliners who varied significantly in proportion by condition. However, only $6-10 \%$ of straightliners could be inferred from their responses in each condition. So, the above issue - the issue of prior knowledge and beliefs affecting how people constructed meaning from the texts - might help to explain the other part. I would encourage the authors to analyze and report any findings they have (or have not reported) which explore how responses in the baseline data help to resolve the mechanism for the null results.

\section{Methodological issues:}

Because the researchers apparently did not measure prior knowledge of genetics or genetic beliefs prior to reading, then this could also be discussed as a methodological limitation of the present experiment.

The theoretical and empirical rationale for testing a shorter treatment given in the introduction is not convincing nor is it compelling. For example, the authors state, "The purpose of this study is threefold. First, the main goal is to test if the persuasion effect $(\mathrm{H} 1)$ and the genetic interpolation effect $(\mathrm{H} 2)$ also emerge following exposure to a softer treatment. Addressing this issue is necessary to better capture what kind of message can trigger the genetic interpolation effect". If this study is telling us anything about the world, then it should tell us what it is actually modeling in the world through the experimental design. For example, is the shorter reading on behavioral genetics more akin to what science students might read in a textbook, and thus, worth investigating? Or, is it the kind of message that people might come across on PubMed? In short, why is the shorter reading important to investigate?

There are four conditions and 2080 participants. Given that the main finding in this study is a null finding, some care and effort needs to be taken to explain the a priori power analysis and post-hoc power analysis for the trial. For example, if the experiment is underpowered, then the significance of the null finding is diminished if not destroyed.

This issue is exacerbated by the multiple comparisons in the study. With four groups in the study 
there are three comparisons that can be made with the control group. Then, there are three different measures. So, in sum total there are at least nine-different statistical tests that could be run to test hypotheses. The authors should outline which of these tests are the confirmatory tests and which are the exploratory tests. Alpha values, and hence p-values, should be adjusted to account for Type-I error on the confirmatory tests. And, then, based on the actual effect sizes, and the adjusted alpha criterion, the authors should report what their post-hoc power was on each test. If the reach $80 \%$ power and their finding is still null, then such a null finding, in my mind, is worthy of indexing. However, if the authors were underpowered, then the contribution of these findings to the research community is less clear.

If we take the authors at their word, then with 2080 people in their panel and a response rate of $62.6 \%$, there are about 1300 people enrolled in the experiment. If we divide that number in half ( $\mathrm{n}$ $=650$ ), that is the amount of people present in any single comparison with the control. Then, we can divide $0.05 / 3$ to account for the three different variables per treatment-control contrast. If we assume there is no baseline data which would improve the precision of the estimate by increasing the R2 in the models, then any single treatment-control contrast could detect an effect size of $d=$ 0.25 or greater. If we, instead, adjust alpha to account for all possible treatment control contrasts on all variables (i.e. 9 tests or $0.05 / 9=0.0055$ ), then effects of $d=0.28$ or greater should be detectable. So, the question is, how big were the effects. Unfortunately, the standard deviation for the control group is not reported, nor are the pairwise effect sizes. If the authors provided that information, then the readers would have more confidence that the null effects are significant and merit indexing.

Competing Interests: No competing interests were disclosed.

I confirm that I have read this submission and believe that I have an appropriate level of expertise to confirm that it is of an acceptable scientific standard, however I have significant reservations, as outlined above.

Author Response 08 Dec 2016

Alexandre Morin-Chassé, Université de Montréal, Montréal, Canada

M. Donovan, thanks for your careful reading of this paper. Your suggestions and critiques will help get the most out of this study. I will wait until I receive additional reviews and devote some time in January to work on writing a revised version which will address all of your concerns.

Competing Interests: No competing interests were disclosed.

\section{Comments on this article}

\section{Version 1}




\section{Author Response 06 Feb 2017}

Alexandre Morin-Chassé, Université de Montréal, Montréal, Canada

Dear reviewers, this is just a short message to inform you that I am currently working on writing a revised version of my paper that will address your reservations. I expect to submit this second version during the last week of February. Thanks for your insights and your patience.

Competing Interests: No competing interests were disclosed.

The benefits of publishing with F1000Research:

- Your article is published within days, with no editorial bias

- You can publish traditional articles, null/negative results, case reports, data notes and more

- The peer review process is transparent and collaborative

- Your article is indexed in PubMed after passing peer review

- Dedicated customer support at every stage

For pre-submission enquiries, contact research@f1000.com 